\title{
Origen y microdiferenciación de la población humana del Archipiélago de Chiloé
}

\author{
Origin and microdifferentiation of the human Chiloé Archipelago population
}

\author{
FEDERICO GARCÍA ${ }^{1}$, MAURICIO MORAGA ${ }^{1}$, SOLEDAD VERA ${ }^{1}$, HUGO HENRÍQUEZ $^{1}$, ELENA LLOP ${ }^{1}$, \\ CARLOS OCAMPO $^{2}$, EUGENIO ASPILLAGA ${ }^{1,2}$ \& FRANCISCO ROTHHAMMER ${ }^{1,3^{*}}$
}

\begin{abstract}
${ }^{1}$ Programa de Genética Humana-ICBM, Facultad de Medicina, Universidad de Chile, Santiago, Chile ${ }^{2}$ Departamento de Antropología, Facultad de Ciencias Sociales, Universidad de Chile, Santiago, Chile ${ }^{3}$ Centro de Investigaciones del Hombre en el Desierto, Universidad de Tarapacá, Arica, Chile *Autor para correspondencia: frothham@med.uchile.cl
\end{abstract}

\begin{abstract}
RESUMEN
Las etnias originarias del archipiélago de Chiloé presentan características culturales que plantean preguntas acerca de su origen como entidad genética independiente y distinta del grupo continental. Al respecto, hemos caracterizado las frecuencias de los cuatro haplogrupos amerindios fundadores del ADN mitocondrial en cuatro poblaciones del archipiélago. El componente aborigen materno de estas poblaciones fue superior al 90 $\%$. El análisis de distancias genéticas sugiere una segregación norte-sur en donde las poblaciones septentrionales aparecen más relacionadas con la etnia continental Huilliche. Aun cuando el análisis de diferenciación interpoblacional y de componentes principales muestran una singularidad en el grupo insular, esta puede ser interpretada a partir de datos genéticos, etnohistóricos y arqueológicos.
\end{abstract}

Palabras clave: Chiloé, diversidad étnica, diversidad genética humana, ADN mitocondrial.

\begin{abstract}
The cultural diversity of Chiloé archipelago's population raises questions about its ethnic origin. To determinate whether this population forms a distinct genetic-cultural entity in relation to continental groups, four populations were characterized genetically. Gene frequencies for the four Amerindian mitochondrial DNA haplogroups were analyzed. The studied groups exhibit an important aboriginal maternal genetic contribution since over $90 \%$ of the individuals analyzed presented Amerindian mtDNA haplogroups. Although the genetic distance analysis indicates a north-south segregation, in agreement with ethnohistoric information, a relationship between groups of the Northern part of the archipelago with the Huilliche population is observed. Nevertheless, the exact test of population differentiation and the principal component analysis indicate a singularity in the insular group which can be explained combining genetic, ethnohistoric and archeological data.
\end{abstract}

Key words: Chiloé, ethnic diversity, human genetic diversity, mitochondrial DNA.

\section{INTRODUCCIÓN}

Las particularidades culturales de las poblaciones del archipiélago de Chiloé han sido objeto de varios estudios antropológicos (Munizaga 1978, Croese 1980, Grenier 1984). Desde el punto de vista lingüístico, se ha descrito un dialecto propio que tendría un $85 \%$ de homología con el mapudungún de la cultura Mapuche (Croese 1980). Los contactos interétnicos entre poblaciones heterogéneas del archipiélago incidirían en la configuración cultural y genético-molecular de los asentamientos chilotes (Cooper 1917).
El confuso mapa etnográfico del archipiélago de Chiloé, sin duda, se relaciona con la presión ejercida por las poblaciones continentales del norte de Chiloé hacia las poblaciones canoeras asentadas en el archipiélago. Este efecto se complejiza aún más con la colonización española y presencia de Jesuitas, importantes agentes de traslado, confinamiento y mezcla en los canales septentrionales (Ocampo comunicación personal). Desde este punto de vista, los Chonos se constituyen como la expresión tardía de los canoeros que habrían incorporado numerosos elementos culturales de los grupos horti- 
cultores continentales del norte. Así, los grupos canoeros constituirían el sustrato poblacional de los grupos del archipiélago y del grupo Chono de tiempos históricos, cuya afinidad cultural y aspecto físico los acerca a los canoeros del extremo sur (Cooper 1917). La información cultural y bioantropológica reunida a principios del siglo XX permitió vincularlos preliminarmente con las poblaciones fueguinas (Latcham 1911). Investigaciones recientes a través de haplogrupos mitocondriales indican que los fueguinos tanto históricos como tempranos, poseen solo dos de los cuatro linajes fundadores, y representan probablemente a una primera oleada migratoria (García-Bour et al. 1998). Por su parte, los hallazgos arqueológicos son consistentes con una población de adaptación marítima, que desde hace 6.500 años habría colonizado el Seno de Reloncaví e isla Grande de Chiloé (Aspillaga et al. 1995, Rivas et al. 1999), hasta las islas Guaitecas (Ocampo \& Aspillaga 1984). Además, el desgaste dentario, la presencia de osteoma en el conducto auditivo del cráneo, el desarrollo de algunas inserciones y lesiones en los huesos largos sugieren una temprana adaptación al entorno costero de los canales patagónicos septentrionales (Rivas et al. 1999). Estos ocupantes tempranos de adaptación marítima introducen cambios a su modo de vida, en tiempos tardíos como resultado de la penetración de grupos continentales, probablemente Huilliches, en el archipiélago. No obstante, persisten elementos culturales unificadores de la cultura regional hasta el presente (Rivas \& Ocampo comunicación personal). A la llegada de los españoles la etnia Chonos, de surgencia protohistórica, se encontraba replegada hacia el extremo meridional del archipiélago; actual ubicación de la comunidad de Laitec (Fig.1). Considerando estos elementos hemos sometido a prueba la hipótesis nula de homogeneidad genética de los grupos étnicos del archipiélago de Chiloé. Se han analizado los linajes mitocondriales de poblaciones de los extremos norte y sur del archipiélago y contrastado los resultados con aquellos de poblaciones aborígenes del sur de Chile. Adicionalmente, para evaluar el flujo génico entre las fracciones septentrional y meridional, se han analizado muestras de una población ubicada en el centro del archipiélago de Chiloé.

\section{MATERIALES Y MÉTODOS}

Se incluyeron 47 individuos no emparentados, residentes de la localidad de Carelmapu $\left(41^{\circ} 45^{\prime} \mathrm{S}, 73^{\circ} 44^{\prime} \mathrm{O}\right), 42$ individuos de Quetal- mahue $\left(41^{\circ} 45^{\prime} \mathrm{S}, 73^{\circ} 55^{\prime} \mathrm{O}\right), 27$ individuos de Detif $\left(42^{\circ} 40^{\prime} \mathrm{S}, 73^{\circ} 35^{\prime} \mathrm{O}\right)$ y 42 individuos de

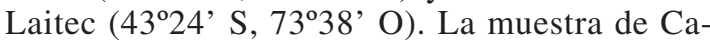
relmapu representa el $1,75 \%$ de los habitantes de esa localidad, las de Quetalmahue y Detif representan alrededor del $7 \%$, mientras que la de Laitec alcanza al 16,5\%. Mediante información del lugar de nacimiento de los sujetos tipificados y de sus antecesores, se puede estimar que los habitantes de estas localidades presentan una movilidad moderada y acotada a su lugar de origen. Por ello es posible suponer que las cuatro localidades caracterizadas representan en términos generales la estructura poblacional del archipiélago de Chiloé (Munizaga 1978).

Las muestras de sangre se obtuvieron hace 10 años, con consentimiento verbal, según se usaba en aquella época. Luego de la centrifugación de una alícuota de sangre de $10 \mathrm{~mL}$ se obtuvo un concentrado leucocitario (buffy coat) desde el cual posteriormente se extrajo el ADN (Gustincich et al. 1991). Se amplificó por PCR la región intergénica $\mathrm{V}$ del $\mathrm{ADN}$ mitocondrial (ADNmt) y los otros tres fragmentos que contienen los RFLPs característicos de poblaciones amerindias, utilizando los partidores descritos por Moraga et al. (2000). La reacción de amplificación se realizó en un volumen final de $50 \mu \mathrm{l}$ que contenía $300 \mathrm{ng}$ de $\mathrm{ADN}$, una unidad de Taq polimerasa (Promega), 25 pmoles de cada partidor, $1,5 \mathrm{mM} \mathrm{MgCl} 2,200 \mathrm{nM}$ de cada desoxinucleótido, y el tampón suministrado por la empresa. Las muestras se amplificaron mediante un ciclo de denaturación inicial a $95^{\circ} \mathrm{C}$ por 5 min, 35 ciclos de $95{ }^{\circ} \mathrm{C}$ por $45 \mathrm{seg}, 55^{\circ} \mathrm{C}$ por 1 minuto y $72{ }^{\circ} \mathrm{C}$ por 1 minuto. Se finalizó con un ciclo de extensión a $72{ }^{\circ} \mathrm{C}$ por $5 \mathrm{~min}$. Los fragmentos se digirieron con enzimas de restricción para identificar los polimorfismos que definen los haplogrupos A, B, C y D. El haplogrupo A está definido por la presencia de un sitio de restricción Hae III en la posición 663; el haplogrupo B por una delección de 9 pbs en la región intergénica $\mathrm{V}$; el haplogrupo $\mathrm{C}$ por la ausencia de un sitio Hinc II en la posición 13.259; y el haplogrupo D, por la ausencia de un sitio de restricción Alu I en la posición 5.176. Las digestiones enzimáticas y el producto de PCR con la región intergénica $\mathrm{V}$ se analizaron por electroforesis en geles de NuSieveAgarosa al $2 \%$.

La diversidad genética se calculó de acuerdo a Nei (1978). En los análisis sucesivos se incluyeron seis poblaciones aborígenes del sur de Chile. Se consideraron por separado los indígenas fueguinos (Yámana, Alacalufe, Ona y Tehuelche) que fueron obtenidas a partir de res- 


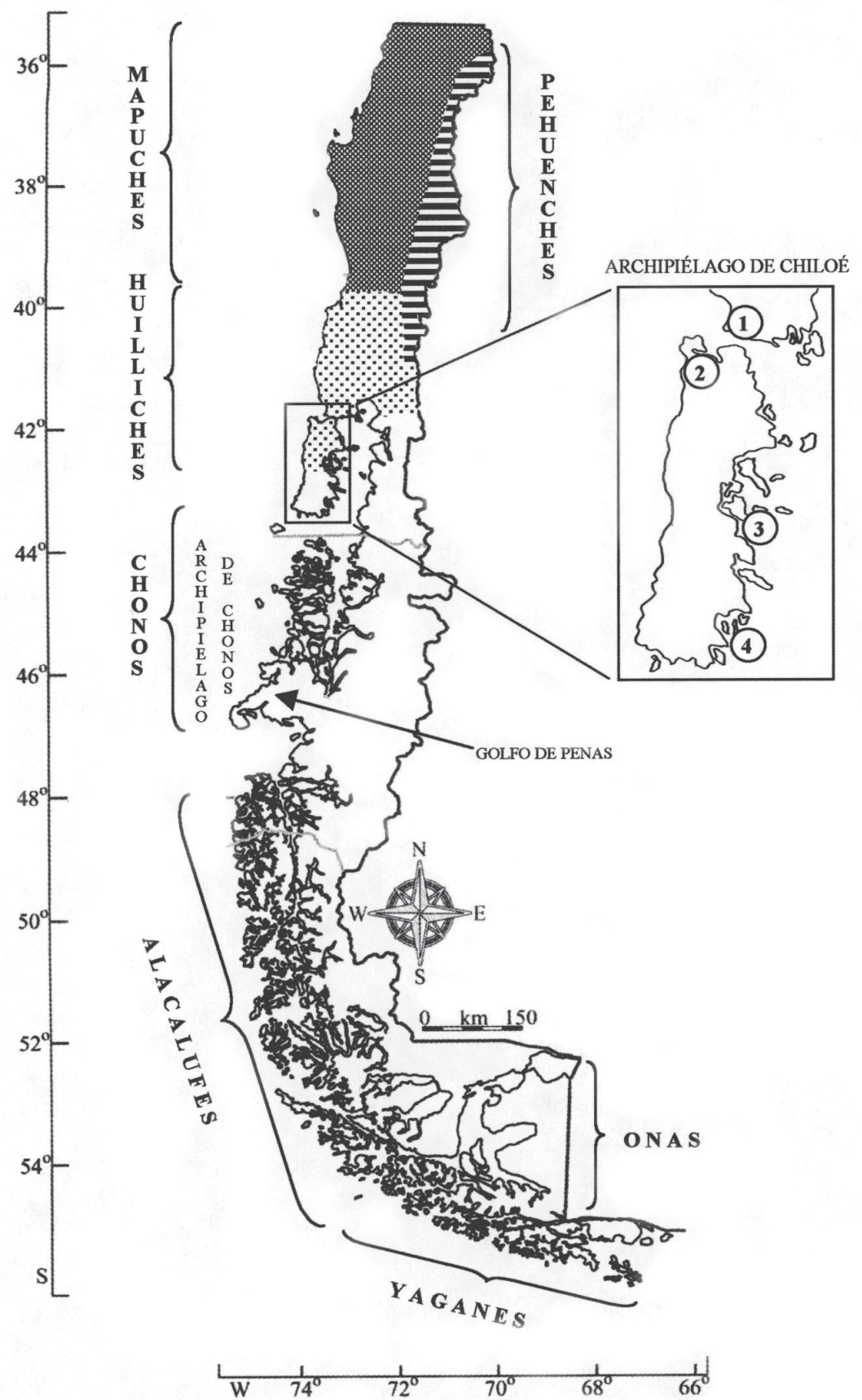

Fig. 1: Mapa de Chile que muestra la ubicación de las poblaciones consideradas en este estudio; 1Carelmapu, 2-Quetalmahue, 3-Detif, 4-Laitec.

Map of Chile showing the characterized populations in Chiloé archipelago: 1-Carelmapu, 2-Quetalmahue, 3-Detif, 4Laitec. 
tos óseos antiguos (Lalueza et al. 1996), de la población Yámana actual (Moraga et al. 2000).

Las diferencias genéticas entre poblaciones se establecieron mediante comparaciones pareadas, usando los estadígrafos Fst (Wright 1951) del programa GDA 1.0 (Lewis \& Saykin 2001) para datos haploides. Cada Fst fue calculado como Theta $=(\mathrm{PCE}-\mathrm{PCD}) /\left(\mathrm{PCE}+\left(\mathrm{n}_{\mathrm{c}}-\right.\right.$ 1) $x$ PCD), donde PCE es el promedio al cuadrado de las diferencias entre poblaciones. PCD es el promedio al cuadrado de las diferencias observadas dentro de las poblaciones y $\mathrm{n}_{\mathrm{c}}$ es el número de haplotipos. Bajo la hipótesis de homogeneidad entre poblaciones, se obtiene la distribución nula de estos valores permutando haplotipos entre poblaciones. Así, P representa la proporción de permutaciones que conduce a un valor de Fst mayor o igual al observado (Schneider et al. 2000).

Mediante normalización de las distancias con el tiempo de divergencia entre poblaciones, los valores pareados de Fst reflejan la diferenciación genética a corto plazo (Reynolds et al. 1983). La matriz de distancias de Fst fue representada mediante un dendrograma "neighbor-joining" (Saitou \& Nei 1987) utilizando el programa MEGA 2.1 (Kumar et al. 2001), y por un análisis de componentes principales (Cavalli-Sforza et al. 1994). Este procedimiento permite resumir una matriz de distancias multidimencional en un mapa de componentes principales de dos dimensiones, que retienen la mayor parte de la varianza genética (Harpending et al. 1996, Stoneking et al. 1997). Se realizó 10.000 replicas "bootstrap" a los datos considerados como varios loci con múltiples alelos (Merriwether et al. 1995).

\section{RESULTADOS}

Se tipificaron 158 muestras para los cuatro haplogrupos mitocondriales característicos de poblaciones amerindias. Sus frecuencias mostraron que la tasa de mezcla aborigen materna supera el $95 \%$ en estas poblaciones (Tabla 1). No se encontraron haplogrupos compuestos y solo 4 individuos $(4,6$ $\%)$ no pertenecieron a alguno de los haplogrupos amerindios, siendo clasificados como "otros".

Los índices de diversidad genética $(\mathrm{H})$ de Nei (1978) (Tabla 1) de las tres poblaciones del norte de la isla de Chiloé son similares al obtenido por Bert et al. (2001) para todas las poblaciones amerindias $(\mathrm{H}=0,697)$. Se encontró un valor mucho más bajo $(\mathrm{H}=0,490)$ en la población meridional de Laitec, que se correlaciona con la presencia de solo dos de los cuatro haplogrupos amerindios.

El dendrograma basado en una matriz de distancias genéticas de haplogrupos muestra dos conglomerados; el primero constituido por poblaciones de filiación Huilliche (conglomerado 1), y el segundo compuesto por poblaciones Mapuches, Pehuenches y Fueguinas (conglomerado 2). Esta segregación, que es avalada por un valor de "bootstrap" de $100 \%$, separa también a las poblaciones del norte y del sur del archipiélago (Fig. 2).

El análisis de componentes principales de la matriz de distancias indica que los primeros vectores propios dan cuenta del 95,4 \% de la varianza (Fig. 3). Los dos conglomerados obtenidos por "neighbor-joining" aparecen nuevamente en esta representación. Complementariamente, el segundo componente separa notoriamente a las

TABLA 1

Distribución de frecuencias y diversidad genética de haplogrupos de ADN mitocondrial (H) en nueve poblaciones chilenas

Frequency distribution and genetic diversity of mitochondrial DNA haplogroups in nine Chilean populations

\begin{tabular}{|c|c|c|c|c|c|c|c|}
\hline \multirow[t]{2}{*}{ Población } & \multicolumn{7}{|c|}{ Haplogrupo } \\
\hline & $\mathrm{N}$ & A & B & $\mathrm{C}$ & $\mathrm{D}$ & Otros & $(\mathrm{H})$ \\
\hline Huilliches ${ }^{1}$ & 80 & 0,038 & 0,288 & 0,188 & 0,488 & 0,000 & $0,652 \pm 0,03$ \\
\hline Carelmapu ${ }^{4}$ & 47 & 0,043 & 0,298 & 0,383 & 0,256 & 0,020 & $0,701 \pm 0,03$ \\
\hline Quetalmahue $^{4}$ & 42 & 0,000 & 0,309 & 0,357 & 0,261 & 0,071 & $0,692 \pm 0,02$ \\
\hline Detif $^{4}$ & 27 & 0.111 & 0.222 & 0.370 & 0.296 & 0.000 & $0,744 \pm 0,04$ \\
\hline Mapuches $^{2}$ & 111 & 0,000 & 0,072 & 0,441 & 0,486 & 0,000 & $0,575 \pm 0,02$ \\
\hline Pehuenches $^{2}$ & 105 & 0,029 & 0,105 & 0,410 & 0,456 & 0,000 & $0,621 \pm 0,02$ \\
\hline Laitec $^{4}$ & 42 & 0,000 & 0,000 & 0,357 & 0,571 & 0,071 & $0,490 \pm 0,04$ \\
\hline Fueguinos $3 *$ & 45 & 0,000 & 0,000 & 0,422 & 0,568 & 0,022 & $0,524 \pm 0,03$ \\
\hline Yámanas ${ }^{2}$ & 21 & 0,000 & 0,000 & 0,480 & 0,520 & 0,000 & $\begin{array}{r}0,520 \pm 0,04 \\
\text { Media }=0,599\end{array}$ \\
\hline
\end{tabular}

${ }^{1}$ Merriwether et al. (1995), ${ }^{2}$ Moraga et al. (2000), ${ }^{3}$ Lalueza et al. (1996), ${ }^{4}$ Este estudio.

*Las frecuencias de Fueguinos fueron obtenidas a partir de restos esqueletales 


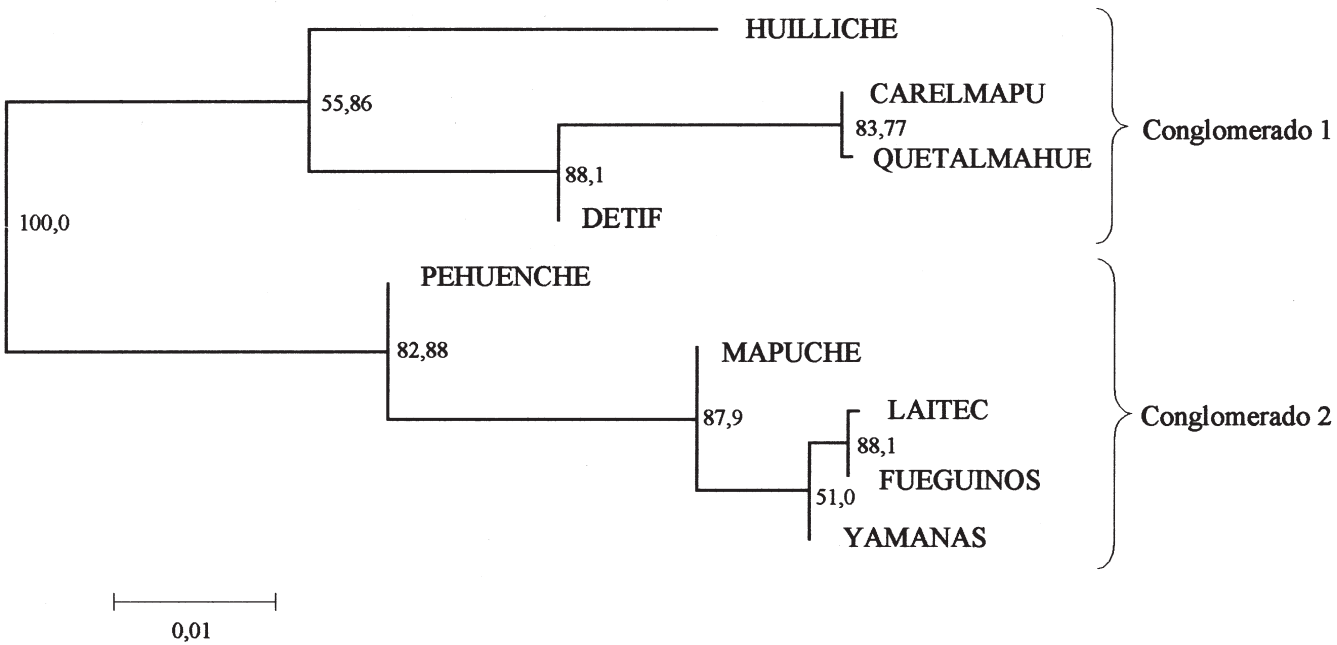

Fig. 2: Dendrograma (neighbor-joining) basado en la matriz de distancias del ADNmt. Números indican valores de "bootstrap".

Neighbor-joining dendrogram based on distance matrix of mtDNA. Numbers indicate bootstrap values.

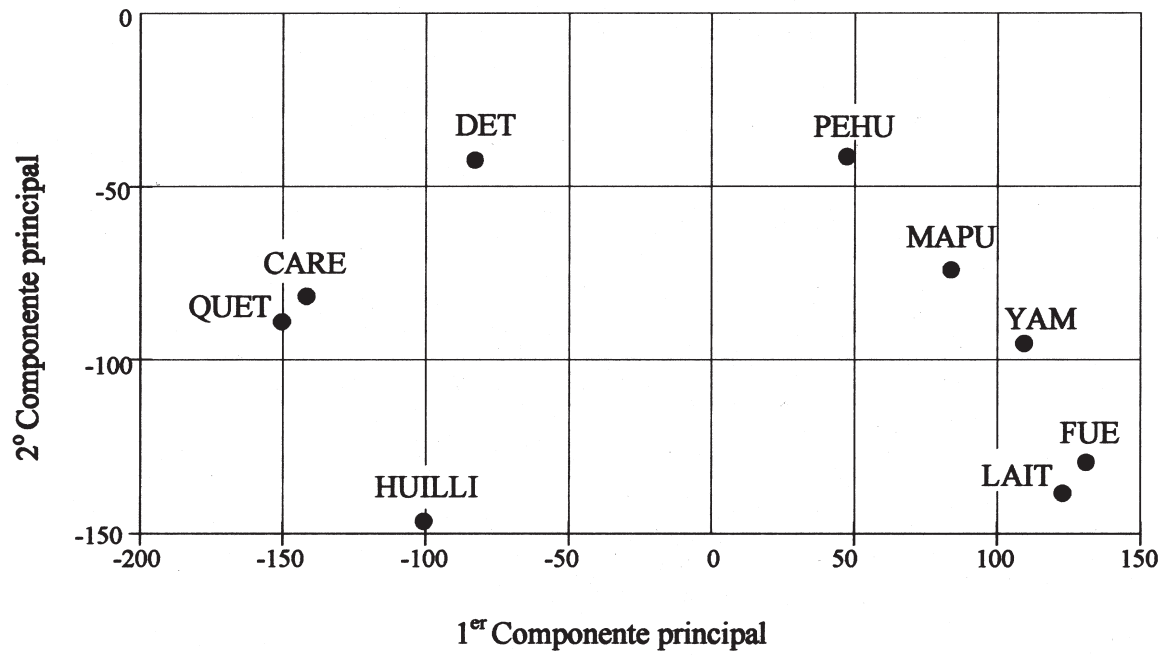

Fig. 3: Análisis de componentes principales de la matriz de distancias entre 9 poblaciones chilenas. Las muestras están codificadas como: HUILLI-Huilliches, QUET-Quetalmahue, CARE-Carelmapu, DET-Detif, PEHU-Pehuenches, MAPU-Mapuches, YAM-Yámanas, FUE-Fueguinos, LAIT-Laitec.

Principal components analysis of distance matrix among nine Chilean populations. Samples are coded: HUILLI-Huilliche, QUET-Quetalmahue, CARE-Carelmapu, DET-Detif, PEHU-Pehuenches, MAPU-Mapuches, YAM-Yámanas, FUE-Fueguinos, LAIT-Laitec. 
poblaciones de Chiloé septentrional de los Huilliches, grupo que se ubica en coordenadas extremas y opuestas a las del grupo insular.

En la comparación entre pares de poblaciones, la prueba de permutación de haplotipos entre poblaciones muestra que no existen diferencias estadísticamente significativas entre las poblaciones de Chiloé septentrional (Carelmapu, Quetalmahue y Detif) (Tabla 2). Estos grupos aparecen relacionados con la etnia Huilliche, aun cuando las diferencias Carelmapu-Huilliches ( $\mathrm{P}$ $=0,01426 \pm 0,0010)$ y Quetalmahue-Huilliches $(\mathrm{P}=0,02247 \pm 0,0016)$, resultan significativas confirmando la singularidad del grupo chilote en relación a sus vecinos continentales. Además, todas las poblaciones de Chiloé septentrional presentan diferencias significativas con la población de Laitec. Ello permite rechazar la hipótesis nula y plantear una segregación genética nortesur en el archipiélago.

En la comparación entre conglomerados se observa diferencias significativas en todos los casos, con excepción de los pares Detif-Pehuenches $(\mathrm{P}=0,191996 \pm 0,0037)$ y Detif-Yámanas $(\mathrm{P}=0,1008 \pm 0,0031)$. La composición genética de Detif, ubicada en el centro geográfico del archipiélago, se acerca a la tendencia observada en el segundo conglomerado, aunque se agrupa dentro del primero.

\section{DISCUSIÓN}

El análisis de las frecuencias de haplogrupos del ADNmt permite identificar una segregación genética norte-sur en el archipiélago, posiblemente relacionada con el origen étnico de las poblaciones. El grupo de Chiloé septentrional aparece relacionado con la etnia Huilliche, mientras que el grupo meridional está vinculado con poblaciones fueguinas. Al respecto, es importante destacar la ausencia de los haplogrupos A y B en Laitec, tal y como ocurre en Yámanas y Fueguinos.

Si se presume que Laitec representa un reservorio genético de los extintos Chonos, se podría inferir un origen fueguino para dicha etnia. Esta tesis es consistente con antecedentes etnolinguíticos que apoyan la diferenciación dialéctica entre las poblaciones del Sur del archipiélago de Chiloé respecto del idioma Mapuche (Latcham 1928).

Aunque las poblaciones de la fracción septentrional aparecen relacionadas con la etnia Huilliche, su composición revela un fenómeno

TABLA 2

Valores de P para la prueba de Fst entre todos los pares de poblaciones incluidas en este estudio*

P-values for Fst test among all pairs of populations compared in the study

\begin{tabular}{|c|c|c|c|c|c|c|c|c|}
\hline & Huilliche & Carelmapu & Quetalmahue & Detif & Laitec & Pehuenche & Mapuche & Fueguinos \\
\hline Carelmapu & $\begin{array}{r}0,01426 \\
\pm 0,0010\end{array}$ & & & & & & & \\
\hline Quetalmahue & $\begin{array}{r}0,02247 \\
\pm 0,0016\end{array}$ & $\begin{array}{r}0,93545 \\
\pm 0,0027\end{array}$ & & & & & & \\
\hline Detif & $\begin{array}{r}0,07712 \\
\pm 0,0028\end{array}$ & $\begin{array}{r}0,81913 \\
\pm 0,0032\end{array}$ & $\begin{array}{r}0,60350 \\
\pm 0,0042\end{array}$ & & & & & \\
\hline Laitec & $\begin{array}{r}0,00307 \\
\pm 0,0006\end{array}$ & $\begin{array}{r}0,00188 \\
\pm 0,0004\end{array}$ & $\begin{array}{r}0,00168 \\
\pm 0,0004\end{array}$ & $\begin{array}{r}0,02742 \\
\pm 0,0015\end{array}$ & & & & \\
\hline Pehuenche & $\begin{array}{r}0,00238 \\
\pm 0,0005\end{array}$ & $\begin{array}{r}0,01772 \\
\pm 0,0013\end{array}$ & $\begin{array}{r}0,01861 \\
\pm 0,0012\end{array}$ & $\begin{array}{r}0,19196 \\
\pm 0,0037\end{array}$ & $\begin{array}{r}0,18622 \\
\pm 0,0037\end{array}$ & & & \\
\hline Mapuche & $\begin{array}{r}0,00059 \\
\pm 0,0002\end{array}$ & $\begin{array}{r}0,00465 \\
\pm 0,0006\end{array}$ & $\begin{array}{r}0,00485 \\
\pm 0,0008\end{array}$ & $\begin{array}{r}0,04854 \\
\pm 0,0026\end{array}$ & $\begin{array}{r}0,24641 \\
\pm 0,0040\end{array}$ & $\begin{array}{r}0,68567 \\
\pm 0,0056\end{array}$ & & \\
\hline Fueguinos & $\begin{array}{r}0,00059 \\
\pm 0,0002\end{array}$ & $\begin{array}{r}0,00297 \\
\pm 0,0005\end{array}$ & $\begin{array}{r}0,00168 \\
\pm 0,0004\end{array}$ & $\begin{array}{r}0,03336 \\
\pm 0,0019\end{array}$ & $\begin{array}{r}0,74250 \\
\pm 0,0043\end{array}$ & $\begin{array}{r}0,27928 \\
\pm 0,0042\end{array}$ & $\begin{array}{r}0,48827 \\
\pm 0,0047\end{array}$ & \\
\hline Yámana & $\begin{array}{r}0,00980 \\
\pm 0,0009\end{array}$ & $\begin{array}{r}0,02000 \\
\pm 0,0015\end{array}$ & $\begin{array}{r}0,01653 \\
\pm 0,0014\end{array}$ & $\begin{array}{r}0,10088 \\
\pm 0,0031\end{array}$ & $\begin{array}{r}0,52322 \\
\pm 0,0050\end{array}$ & $\begin{array}{r}0,56420 \\
\pm 0,0049\end{array}$ & $\begin{array}{r}0,76200 \\
\pm 0,0043\end{array}$ & $\begin{array}{r}0,80111 \\
\pm 0,0040\end{array}$ \\
\hline
\end{tabular}

* Se han señalado en gris los resultados para las pruebas de Fst entre pares de poblaciones pertenecientes al mismo conglomerado 
de microdiferenciación genética que podría ser explicado tanto desde un punto de vista cultural como biogeográfico. Al respecto, las poblaciones Huilliches del norte del archipiélago no tienen acceso a los recursos del mar debido a la costa escarpada, el singular bosque laurifolio, excesivamente húmedo, denso e impenetrable. En este sector el modo de vida agrícola-ganadero se ha manifestado como alternativa paralela al sistema costero (Gazmuri \& Reveco, 1994). En contraste, el potencial marítimo es enteramente explotable 200 kilómetros al sur, donde las extensas terrazas marinas sustentan una gran riqueza de moluscos bivalvos. Esta disparidad geográfica ha repercutido sobre el modo de vida y la economía local de los habitantes de esta zona. Llagostera (1996) ha indicado que las economías costera y continental no son complementarias sino competitivas y que este antagonismo habría propiciado el aislamiento y singularidad cultural del grupo chilote. Por ende, los grupos continentales y costeros habrían mantenido un flujo génico moderado, siguiendo historias microevolutivas diferentes.

La información genética y etnohistórica presentada en este trabajo permite realizar algunas inferencias sobre las relaciones ancestrales entre poblaciones del archipiélago de Chiloé y regiones aledañas. Cabe destacar que el ADNmt es particularmente útil en el análisis de relaciones de parentesco entre poblaciones mestizas, debido al hecho que el ADN nuclear de estas poblaciones incorporó precozmente un alto porcentaje de genes caucasoides como consecuencia de la llegada de los conquistadores europeos, que en su gran mayoría eran varones. El aporte al acervo genético mitocondrial de mujeres españolas fue bastante posterior y reducido (Rothhammer \& Cruz-Coke 1983).

\section{AGRADECIMIENTOS}

Los autores agradecen al Editor Asociado Dr. Milton Gallardo por sus valiosos comentarios y sugerencias. Agradecemos además el financiamiento recibido a través del proyecto FONDECYT 1010131. En la preparación de este artículo se integró además información recopilada en el marco de ejecución del proyecto FONDECYT 1020616.

\section{LITERATURA CITADA}

ASPILLAGA E, C OCAMPO, JC OLIVARES, B ARENSBURG \& J MEYER (1995) Una visita a los canoeros de Quetalmahue Dirección de Bibliotecas, Archivos y Museos. Museos (Chile) 20: 18-20.
BERT F, A CORELLA, M GENÉ, A PÉREZ-PÉREZ \& D TURBÓN (2001) Major mitochondrial DNA heterogeneity in highland and lowland Amerindian Populations from Bolivia. Human Biology 73: 1-16.

CAVALLI-SFORZA LL, P MENOZZI \& A PIAZZA (1994) The history and geography of human genes. Princeton University Press, Princeton, New Jersey, USA. $510 \mathrm{pp}$.

COOPER J M (1917) Analytical and critical bibliography of the tribes of Tierra del Fuego and adjacent territory. Bulletin 63, Bureau of American Ethnology, Smithsonian Institution. House Documents Volume 28, Government Printing Office, Washington, District of Columbia, USA.

CROESE R (1980) Estudio dialectológico del mapuche. Estudios Filológicos (Chile) 15: 7-38.

GARCÍA-BOUR J, A PÉREZ-PÉREZ, E PRATS \& D TURBON (1998) Secuencias de mtDNA de aborígenes de la Tierra del Fuego-Patagonia y el origen de los fueguinos. Anales del Instituto de la Patagonia 26: 69-75.

GAZMURI S \& A REVECO (1994) Perfil etnográfico de la comunidad huilliche de isla Huapi. Tesis de Licenciatura, Facultad de Filosofía y Humanidades, Universidad Austral, Valdivia, Chile. 40 pp.

GRENIER P (1984) Chiloé et les chilotes, marginalité et dépendance en Patagonie chilienne: étude de géographie humaine. EDISUD, Aix-en-Provence, France. 190 pp.

GUSTINCICH S, G MANFIOLETTI, G DEL SAL, C SHNEIDER \& P CARNINCI (1991) A fast method for high quality genomic DNA extraction from whole blood. Biotechniques 11: 298-302.

HARPENDING HC, JH RELETHFORD \& ST SHERRY (1996) Methods and models for understanding human diversity. En: Boyce AJ \& CGN MascieTaylor (eds) Molecular Biology and Human Diversity: 283-299. Cambridge University Press, London, United Kingdom.

KUMAR S, K TAMURA, IB JEKOBSEN \& M NEI (2001) Mega 2.1: Molecular Evolutionary. Genetics Analysis Software. Arizona State University, Tempe, Arizona, USA.

LATCHAM R (1911) Antropología Chilena. Trabajos del primer congreso científico panamericano. Vol XIV. Santiago, Chile, 256 pp.

LATCHAM R (1928) El problema del origen de los Araucanos. Revista Universitaria 12 (Chile): 17-26.

LALUEZA C. (1996) Mitochondrial DNA haplogrupos in four tribes from Tierra del Fuego-Patagonia: inferences about the peopling of Americas. Human Biology 68: 855-871.

LEWIS PO \& D ZAYKIN. (2001) Genetic Data Analysis: computer program for the analysis of allelic data. Version $1.0(\mathrm{~d} 16 \mathrm{c})$.

LLAGOSTERA A (1996) Caza y pesca marítima del 9.000 a 1000 a.C. En: Hidalgo (eds) 76-79. Culturas de Chile Prehistoria: Desde sus orígenes hasta los albores de la conquista. Editorial Andrés Bello, Santiago, Chile.

MERRIWETHER A, F ROTHHAMMER \& R FERRELL (1995) Distribution of the four founding lineage haplotypes in Native Americans suggests a single wave of migration for the New Word. American Journal of Physical Anthropology 98: 411-430.

MORAGA M, P ROCCO, J MIQUEL, F NERVI, E LLOP, R CHAKRABORTY, F ROTHHAMMER \& P CARVALLO (2000) Mitochondrial DNA polymorphisms in Chilean aboriginal populations: implications for the peopling of the southern cone 
of the continent. American Journal of Physical Anthropology 113: 19-29.

MUNIZAGA JR (1978) Microevolución en poblaciones rurales contemporáneas de Chiloé. Revista Chilena de Antropología (Chile) 1: 143-153

NEI M (1978) Estimation of average heterozygosity and genetic distance from a small number of individuals. Genetics 89: 583-590.

OCAMPO C \& E ASPILLAGA (1984) Breves notas sobre una prospección arqueológica en los archipiélagos de las Guaitecas y los Chonos. Revista Chilena de Antropología 4: 155-156.

OCAMPO C \& P RIVAS (en prensa) El poblamiento marítimo de los canales occidentales de la Patagonia: desde Chiloé hasta el Cabo de Hornos. Mar del Sur. Editorial Ocho Libros, Santiago, Chile.

REYNOLDS J, BS WEIR \& CC COCKERHAM (1983) Estimation on the coancestry coefficient: basis for a short-term genetic distance. Genetics 105: 767-779.

RIVAS P, C OCAMPO \& E ASPILLAGA (1999) Poblamiento temprano de los canales Patagónicos:
El núcleo ecotonal septentrional. Anales Instituto de la Patagonia 27: 221-230.

ROTHHAMMER F \& R CRUZ-COKE (1983) Flujo génico y deriva génica. Curso básico de genética humana. Editorial Universitaria, Santiago, Chile. vii +265 pp.

SAITOU N \& M NEI (1987) The neighbor-joining method: a new method for reconstructing phylogenetic trees. Molecular Biology and Evolution 4: 406-425.

SCHNEIDER S, D ROESSLI \& L EXCOFFIER (2000) Arlequin version 2000: a software for population genetics data analysis. Genetics and Biometry Laboratory, University of Geneva, Switzerland.

STONEKING M, JJ FONTIUS, SL CLIFFORD, H SOODYALL, SS ARCOT, N SAHA, T JENKINS, MA TAHIR, PL DEININGER \& MA BATZER (1997) Alu insertion polymorphisms and human evolution: evidence for a larger population size in Africa. Genome Research 7: 1061-1071.

WRIGHT S (1951) The genetical structure of populations. Ann Eugen 15: 323-354.

Editor Asociado: Milton Gallardo

Recibido el 4 de diciembre de 2003; aceptado el 3 de junio de 2004 